\title{
How modifications of China's energy data affect carbon mitigation targets
}

Heran Zheng ${ }^{1}$, Yuli Shan ${ }^{1}$, Zhifu $\mathrm{Mi}^{2}$, Jing Meng ${ }^{3}$, Jiamin $\mathrm{Ou}^{1}$, Heike Schroeder ${ }^{1}$, and Dabo Guan $^{1 *}$

1. Tyndall Centre for Climate Change Research, School of International Development, University of East Anglia, Norwich NR4 7TJ, UK

2. The Bartlett School of Construction and Project Management, University College London, London, WC1H 0QB, UK.

3. Department of Politics and International Studies, University of Cambridge, Cambridge CB3 9DT, UK.

Correspondence Email: Dabo.guan@uea.ac.uk (Dabo Guan)

Additional Information: The authors declare no competing financial interests.

Author contribution statement: H.Z., Z.M, Y.S, M.J., J.O designed the research; H.Z. wrote the main manuscript text; D.G., H.S conceived the research; and H.Z \& Y.S provided the data and methods. All authors reviewed the manuscript. 


\section{Abstract}

Frequent modifications to energy statistics have led to considerable uncertainty in China's ability to achieve its carbon mitigation targets. Here, we quantitatively measure the impact of energy data revisions on China's ability to achieve its mitigation targets. Our results indicate the following effects of data revisions: 1 . Mitigation challenges have increased by $5 \%$, and the achievement of national mitigation targets (as well as international pledges) might be postponed by two years. 2 . Greater than expected carbon space or emission quota (from 22.94 to $31.31 \mathrm{Gt}$ ) will be obtained from 2015 to $2035.3 . \mathrm{CO}_{2}$ peak levels may become highly uncertain, with the uncertainty varying from $12 \%$ to $29 \%$. In addition to national mitigation targets, data revision has profound implications for key industrial sectors. For example, raw coal consumption by the cement and iron and steel industries has long been underestimated, bringing uncertainty to the achievement of industrial mitigation targets. Our results reveal considerable uncertainty in China's energy data, and this uncertainty suggests that previous mitigation achievements have been overestimated and that the mitigation targets, carbon space values, and peak level estimates proposed by future mitigation schemes may not be reached.

Keywords: Mitigation; China; Uncertainty; Data revision; $\mathrm{CO}_{2}$ inventory 


\section{Introduction}

China's mitigation efforts have become increasingly important for meeting global decarbonisation targets because of China's increasing share of global primary energy consumption and total greenhouse gas (GHG) emissions (Liu, 2015; Shan et al., 2015; van Ruijven et al., 2012). Ambitious mitigation policies have been proposed to reduce the carbon emissions from China's carbon-intensive economy, and rigorous mitigation targets have been set to reduce carbon intensity $\left(\mathrm{CO}_{2}\right.$ emissions per unit gross domestic product (GDP)) by $40-45 \%$ by 2020 and $60-65 \%$ by 2030 compared with the 2005 level and to decrease peak carbon emissions by 2030 as promised in the 2014 China-US joint agreement. These ambitious mitigation targets cannot be achieved without a solid national emission inventory that comprehensively describes China's carbon status quo (Guan et al., 2012; Hong et al., 2016; Mi et al., 2017). Unfortunately, because of frequent revisions and inconsistent energy consumption data, China's emission inventory has suffered from considerable uncertainty, and the reliability of this inventory has long been criticised (Korsbakken et al., 2016; Qi and Wu, 2013; Wang, 2011). These inconsistent underlying energy statistics can lead to overor underestimations of national $\mathrm{CO}_{2}$ emissions and cause huge uncertainties in estimates of global emissions (Liu et al., 2015b; Marland et al., 2009), leading to errors in mitigation policies (Bruckner et al., 2014; Gregg et al., 2008; Guan et al., 2012).

Due to the importance of this problem, the inconsistency of energy data has been widely debated (Guan et al., 2012; Ma et al., 2014; Qi et al., 2016). Most studies have focused on the reasons underlying the uncertainty in emission inventories (e.g., under-reporting of energy consumption by small firms and data inflation to fit GDP growth), discussed how to improve the quality of energy data (e.g., employing satellite technology or institutional reform) via different methods or 
investigated means to verify the reliability of these data in comparison with international sources (Akimoto et al., 2006; Guan et al., 2012; Korsbakken et al., 2016; Li et al., 2016; Liu, 2015; Sinton, 2001). Causes related to institutional factors might be too difficult to resolve in the short term, which also implies that ongoing mitigation efforts will be accompanied by uncertainty in the near future. This challenge mainly arises because in a political assessment system that prioritises GDP growth, GDP data are likely to be inflated, while energy data are often manipulated to match the inflated GDP growth (Guan et al., 2011; Guan et al., 2012; Li et al., 2016). Moreover, the impacts of frequent data modifications on the mitigation targets are poorly understood. Here, we quantify the uncertainty in the estimates of $\mathrm{CO}_{2}$ emissions and the likelihood of achieving mitigation targets. We briefly illustrate the latest national energy data modification and compile $\mathrm{CO}_{2}$ emission inventories based on the revised and original data. Using our compiled emission inventory, we quantitatively measure the impacts of the 2015 revision on two national mitigation pledges (the $40-45 \%$ and $60-65 \%$ mitigation targets noted above). Finally, we analyse the effects of the revisions at the sectoral level and their implications for sectoral mitigation.

\section{Background: China's energy data revision}

China has officially revised its energy statistics three times since 2000 (2006, 2010, and 2015)

(Table 1). Such statistics modification is normally periodical in China, following the National Economic Census conducted every 5 years; the National Bureau of Statistics (NBS) uses data from the economic census to validate the historical statistical data collected from the hierarchical statistical system and make adjustments. Each revision has modified the energy balance sheets and final energy consumption by industrial sectors (Guan et al., 2012; Liu, 2015). However, NBS 
does not officially disclose the reasons for revising energy data or how the data were revised. The revisions might be due to the application of new statistical methods or the validation of historical data within economic census data. We assume that new statistical rules or methods would be carried over until the next revision. For example, the new statistical rules and methods applied in the 2010 revision would be applied to statistics from 2008 to 2012. We consider that data revised in a given revision belong to the dataset up to that revision. For example, the 2015 revision revised data from 2000 to 2012, including the 2010 data. Hence, the 2010 revision affected data within the range from 2000 to 2012 . To avoid confusion and facilitate discussion, the data scope of the present research begins in 2000, and energy data provided in the 2015 revision are considered 2015 data (including data from 2000 to 2014); energy data provided in the 2010 revision are considered 2010 data (including data from 2000 to 2012); data provided in the 2006 revision are considered 2006 data (including data from 2000 to 2007); and data provided before the 2006 revision are considered original data (including data from 2000 to 2003).

The data revision details are summarised in Table 1S.

The first energy data revision was conducted in 2006. Based on the first National Economic Census in 2004, NBS revised energy data from 1999 to 2003 in 2006. Compared with the original data, the 2006 data increased total energy consumption by an average of 5\% from 1999 to 2003 . A major change was observed in raw coal and other petroleum products. In the 2006 data, the former increased by an average of $4 \%$, and the latter increased by nearly 4 -fold in comparison with the original data. The second energy revision followed the second National Economic Census in 2008, and energy data from 2000 to 2007 were massively revised by NBS in 2010. The new 2010 data 
revised total energy consumption upward by an average of $7 \%$ from 2000 to 2007 , from $3 \%$ in 2007 to $10 \%$ in 2003 compared with the 2006 data. Compared with the 2006 data, the 2010 data mainly revised the historical consumption of raw coal and coke by average increases of $8 \%$ and $3 \%$, respectively. The third data revision was conducted in 2015 following the third National Economic Census in 2013. This revision modified the energy data from 2000 to 2012, with an average increase in the total energy consumption of $2 \%$. The massive revision occurred especially after 2005, as the discrepancy in total energy consumption between the 2015 data and the 2010 data increased constantly from a 4\% gap in 2005 to an $11 \%$ gap in 2012. In the energy mix, the consumption of raw coal, other washing coal, coke and other gas in the 2015 data was substantially revised from 2000 to 2012, with average increases of 5.9\% (1443 Mt), 9.4\% (103 Mt), 9.3\% (359 Mt), and 129\% (360 Mt), respectively, higher than the 2010 data. Notably, the energy data after 2007 were substantially revised in the 2015 data. According to the change rates for raw coal, other washing coal, and coke during the period from 2007 to 2012, the rates between the 2015 data and the 2010 data increased by $9.1 \%, 17.3 \%, 11.6 \%$, respectively.

Table 1. Comparison among the 2015 data, 2010 data, 2006 data and the original data

\begin{tabular}{c|cccc|cccc}
\hline Item & \multicolumn{6}{|c|}{ Total Energy Consumption (Mtce) } & \multicolumn{4}{c}{ Raw Coal (Mt) } \\
\hline Year & $\begin{array}{c}2015 \\
\text { data }\end{array}$ & $\begin{array}{c}2010 \\
\text { data }\end{array}$ & $\begin{array}{c}2006 \\
\text { data }\end{array}$ & $\begin{array}{c}\text { Original } \\
\text { data }\end{array}$ & $\begin{array}{c}2015 \\
\text { data }\end{array}$ & $\begin{array}{c}2010 \\
\text { data }\end{array}$ & $\begin{array}{c}2006 \\
\text { data }\end{array}$ & $\begin{array}{c}\text { Original } \\
\text { data }\end{array}$ \\
\hline 2000 & $\underline{1,159}$ & $\underline{1,205}$ & $\underline{1,101}$ & 1,036 & $\underline{1,047}$ & $\underline{1,107}$ & $\underline{1,022}$ & 967 \\
2001 & $\underline{1,231}$ & $\underline{1,239}$ & $\underline{1,135}$ & 1,085 & $\underline{1,106}$ & $\underline{1,129}$ & $\underline{1,049}$ & 1,017 \\
2002 & $\underline{1,330}$ & $\underline{1,318}$ & $\underline{1,217}$ & 1,173 & $\underline{1,212}$ & $\underline{1,209}$ & $\underline{1,108}$ & 1,090 \\
2003 & $\underline{1,562}$ & $\underline{1,528}$ & $\underline{1,384}$ & 1,318 & $\underline{1,436}$ & $\underline{1,412}$ & $\underline{1,305}$ & 1,253 \\
2004 & $\underline{1,799}$ & $\underline{1,768}$ & 1,638 & & $\underline{1,644}$ & $\underline{1,615}$ & 1,495 & \\
2005 & $\underline{2,034}$ & $\underline{1,964}$ & 1,873 & & $\underline{\underline{1,856}}$ & $\underline{1,774}$ & 1,650 & \\
2006 & $\underline{2,243}$ & $\underline{2,151}$ & 2,053 & & $\underline{\underline{2,053}}$ & $\underline{1,953}$ & 1,803 & \\
2007 & $\underline{2,412}$ & $\underline{2,292}$ & 2,231 & & $\underline{2,207}$ & $\underline{2,088}$ & 1,936 & \\
2008 & $\underline{2,484}$ & 2,349 & & & $\underline{2,277}$ & 2,136 & & \\
2009 & $\underline{2,671}$ & 2,458 & & & $\underline{2,448}$ & 2,241 & & \\
2010 & $\underline{2,861}$ & 2,625 & & & $\underline{2,590}$ & 2,358 & &
\end{tabular}




\begin{tabular}{l|ll|ll|}
2011 & $\underline{3,141}$ & 2,845 & $\underline{2,886}$ & 2,605 \\
2012 & $\underline{3,258}$ & 2,939 & $\underline{2,978}$ & 2,669 \\
2013 & 3,388 & & 3,092 & \\
2014 & 3,319 & & 2,928 & \\
\hline
\end{tabular}

Note: Mtce=Million tons coal equivalent; Mt=Million tons. Underlined data indicate the revised data for each dataset.

On the industrial level, the energy data revisions mainly revised energy consumption in energy-intensive industries related to raw coal consumption. The raw chemical and cement industries were the most affected. Comparing these industries in the 2015 revision with the 2010 revision, the raw coal consumption in the 2015 revision increased by $41 \%$ (434 Mt) and $21.6 \%$ (425 Mt) for the raw chemical and cement industries, respectively, from 2000 to 2012, which accounted for $53 \%$ of the total raw coal consumption gap from 2000 to 2012 (Figure 1S). These shifts in energy consumption revealed by the data revision indicated a more carbonised China, which directly affects the emissions and thereby poses a threat to the global mitigation initiative. China has set its own mitigation targets as part of its Nationally Determined Contributions (NDCs), which include two core pledges to reduce its carbon intensity by $40-45 \%$ by 2020 (2020 target) and by $60-65 \%$ by 2030 (2030 target). However, the mitigation schemes developed in 2009 and 2014 are based on the 2010 data; therefore, large uncertainties in China's mitigation policymaking and implementation might be generated from uncertain energy data, and these uncertainties further undermine China's ability to achieve its mitigation targets. To assess the impact of energy statistics revision on China's mitigation pledge, we focus on the energy data from the 2010 and 2015 revisions. Data from 2000 to 2014 in the two datasets are compared and analysed.

\section{Materials and Methods}




\subsection{Energy inventory compilation and data source}

All data were obtained from the China Energy Statistics Yearbooks for 2004 to 2015 (NBS, 2004-2015). The China Energy Statistics Yearbooks represent the only official energy data source and are published annually by the NBS. These reports include the national "Energy Balance Sheets" and "Energy Consumption by Sectors Sheets", which provide detailed final energy consumption data for the whole country and by sector (Guan et al., 2012). The energy balance sheets and the sectoral energy consumption are modified after the National Economic Census, and the newly revised energy data are reported in the subsequent yearbook. As this paper focuses on the impact of the statistics revision in the 2014 yearbook on China's ability to achieve its mitigation pledges, we compare two groups of energy data: (1) 2010 data (2000 to 2012), which included energy data from 2000 to 2008 from the China Energy Statistics Yearbook 2009 and energy consumption data from 2000 to 2012 from the China Energy Statistics Yearbooks from 2010 to 2013; and (2) 2015 data (2000 to 2014), which included revised energy data from 2000 to 2013 from the China Energy Statistics Yearbook 2014 and energy consumption data for 2014 from the China Energy Statistics Yearbook 2015. We used two versions of the energy data to compile the energy inventory from 2000 to 2014 . To ensure consistency and comparability between the 2015 data (2000 to 2014) and 2010 data (2000 to 2012), we first extended the 2010 data to 2014 by assuming the same growth rate for 2012 to 2013 and 2013 to 2014 in the 2010 data as that in the 2015 data.

We adopted the sectoral energy consumption approach recommended by the IPCC (Intergovernmental Panel on Climate Change)to calculate the national territorial energy use, which 
is different from the apparent energy consumption approach (Andres et al., 2014; Liu et al., 2015b; Shan et al., 2015). The latter approach is based on the mass balance of fuels for production, domestic and international trade, and stock change. Instead, the approach adopted here is based on energy production and trade data rather than on energy consumption (details can be found in Shan et al., 2015). The total energy consumption for each energy type is calculated using the following equation: total final consumption for each sector + energy used in processing and transforming (thermal power and heating supply) - losses - non-energy use. Following this approach, we prepared the national energy inventory for all the datasets. We collected all final energy consumption data ( 20 fuel types in total) for 47 socioeconomic sectors ( 42 of which are industrial sectors) from the China Energy Statistics Yearbooks. For the secondary energy type (thermal power and heating supply), the energy used in transforming was added to the corresponding sectors. For example, the total energy consumption for electricity generation is the final energy consumption in electricity generation (which is not used to generate electricity) plus the energy used in transforming from primary energy into electricity (transforming coal to electricity). After the losses and non-energy use are removed, the energy inventory can be presented for each energy type used in each socioeconomic sector. A detailed layout of the energy inventory is shown in Supplementary 2. We prepared energy inventories for the original, 2006, 2010 and 2015 datasets, which provide activity data for the subsequent $\mathrm{CO}_{2}$ inventory.

\section{2 $\mathrm{CO}_{2}$ emission inventory}

China publishes carbon per GDP intensity target achievements that can be used with GDP data to estimate "official" $\mathrm{CO}_{2}$ emissions. In this study, the $\mathrm{CO}_{2}$ inventories are based on the energy 
inventories compiled above, which followed the IPCC national GHG inventory guidelines (IPCC, 2006; Peters et al., 2007; Shan et al., 2016). The emissions were calculated using the activity data (the amount of fossil fuels (physical units)) multiplied by the respective emission factor (EF)

(Equation (1)):

$$
\mathrm{CE}=\sum \sum A D_{i j} \times E F_{i j}
$$

where $\mathrm{CE}$ represents the total aggregated $\mathrm{CO}_{2}$ emissions from different energy types $i$ used by sector $j . \mathrm{AD}_{i j}$ (amount of fossil fuels $i$ used in sector $j$ ) represents the fossil fuels combusted, measured in physical units, and $\mathrm{EF}_{\mathrm{ij}}$ represents the emission factors for the fossil fuels $i$ used in sector $j$. EFs can be separated into three parts: the net heating value of each fuel i (TJ per $t$ fuel), which refers to the quantity of heat obtained per unit of fuel; the carbon content $\mathrm{c}$ of each fuel i ( $\mathrm{tC}$ per TJ), which indicates the amount of carbon that could be released per heat unit during combustion; and the oxidisation rate o (\%), which indicates the fraction of fuel i oxidised by each sector during combustion. The sub-factors are specific for the fuel type and sectors (Equation (2)):

$$
\mathrm{CE}=\sum \sum A D_{i j} \times n_{i} \times c_{i} \times o_{i j}
$$

By aggregating the $\mathrm{CO}_{2}$ emissions from different fossil fuels and sectors, we obtained the total $\mathrm{CO}_{2}$ emissions. Although the default value was provided by the IPCC, different EFs were used because local fuel practices contribute to the uncertainty in $\mathrm{CO}_{2}$ emissions (IPCC). In this paper, we refer to the EFs used in Liu's research (Liu et al., 2015b), in which the default EFs used by the IPCC were updated via surveys of coal mines. The results showed that Chinese emissions were overestimated by international institutes (such as IEA, EDGAR) by up to $14 \%$ in 2013 . Following this approach, $\mathrm{CO}_{2}$ emission inventories for each sector and each energy type were compiled; a layout is shown in Supplementary 2. All data can be accessed via China Emission Accounts and 
Datasets (www.ceads.net), a free China energy data sharing platform. The $\mathrm{CO}_{2}$ emissions for different datasets are shown in Figure 2. Based on the $\mathrm{CO}_{2}$ emission inventory for each dataset constructed above, the historical carbon intensity can be calculated by $\mathrm{CO}_{2}$ emissions/GDP. Historical GDP data were collected from the China Statistics Yearbooks from 2001 to 2015.

\section{3 $\mathrm{CO}_{2}$ emission projection}

The Kaya identity is based on the famous IPAT equation

(Impact=Population $\times$ Affluence $\times$ Technology) used to develop identical equations for anthropogenically driven forces (Equation 3) (Kaya, 1990), and the Kaya identity is used to project future GHG emissions in many international projection systems, including the IPCC:

$$
\text { Total emissions }=\text { Population } \times\left(\frac{G D P}{\text { population }}\right) \times\left(\frac{\text { Energy }}{G D P}\right) \times\left(\frac{\text { Emissions }}{\text { Energy }}\right)
$$

The projection equation can be further simplified because of the strong correlation between GDP and $\mathrm{CO}_{2}$ emissions (Blanco et al., 2014) as well as the essentially consistent population size in short-term projections. Changes in $\mathrm{CO}_{2}$ emissions can be driven by increases in economic activities (reflected by the GDP) and changes in the carbon intensity of the economy. Thus, emissions can be decomposed into a simplified Kaya identity (see Equation 4). This method is simple but effective and has been used by Friedlingstein et al. (Friedlingstein et al., 2014). In this paper, we follow the same projection method:

$$
\text { Total emissions }=G D P \times \text { Carbon intenisty }
$$

Therefore, two parts must be projected: the GDP and the carbon intensity.

The first part is GDP projection. Future GDP data (constant price at 2000 levels) were extrapolated based on the growth rate from China's $13^{\text {th }}$ Five Year Plan (2016 to 2020), which 
averaged $6.5 \%$ during the period (NDRC (National Development and Reform Commission), 2015). This growth rate is nearly in accordance with the GDP forecast by the World Bank (shown in Supplementary 2). We assumed that average GDP growth rate was 6\% for 2021 to 2025, 5.5\% for 2026 to 2030, and 5\% for 2031 to 2035. This assumption is based on the trend in China's planned GDP growth rates; these rates were set as 7.5\% for the 11th Five Year Plan (2006-2010), 7\% for the 12th Five Year Plan (2011 to 2015), and 6.5\% for the 13th Five Year Plan (2016 to 2020). Additional details are shown in Table 2 and Supplementary 2.

The second part is the carbon intensity. We assumed that China would maintain the mitigation policy implemented in its $12^{\text {th }}$ Five Year Plan (2011 to 2015), with an average rate of decline of $3.2 \%$ annually in the future. We treat this trend as the typical scenario to evaluate the impact of the data revision in 2015 on achieving the 2020 and 2030 mitigation pledges. We made this assumption because the carbon intensity trajectory is largely affected by mitigation policies developed for the different five-year plans. In the $12^{\text {th }}$ Five Year Plan, mitigation is a key national policy and is implemented in multi-level development plans. We employed a trend analysis (exponential regression) based on historical carbon intensity (2011 to 2014) to project the future trend and evaluate whether China can achieve its mitigation pledges under the mitigation policy of the $12^{\text {th }}$ Five Year Plan.

To determine the uncertainty of China's carbon emission peak level, two other scenarios were introduced to compare with the basic scenario. (1) The accelerated scenario assumes that mitigation would be reinforced in the future; the carbon intensity is projected using the same method as in the $12^{\text {th }}$ Five Year Plan scenario but is based on data obtained for the most recent 5 
years. For example, to project carbon intensity in 2019, the carbon intensity from 2014 to 2018 was used. (2) The alternative scenario is derived from Green and Stern's research, which projects the peak emission time based on updated Chinese socioeconomic data. Their $\mathrm{CO}_{2}$ projection assumes (Green and Stern, 2016) that the GDP growth rate from 2015 to 2020 will average $6.5 \%$ annually and will decrease to $5.5 \%$ from 2020 to 2025 (the rate is assumed to remain the same until 2035). From 2015 to 2020, the energy intensity decreases at a fixed annual rate of $4 \%$, and the $\mathrm{CO}_{2}$ intensity of energy decreases at a fixed rate of $1 \%$ and then increases to $1.5 \%$ thereafter. Compared with the other two scenarios, Green and Stern's scenario can be considered the strictest mitigation scenario, as the carbon intensity decline rate in this scenario is much higher than those in the others (e.g., $5.44 \%$ for $2020-2035$ in Green and Stern's scenario and $4.59 \%$ in the $12^{\text {th }}$ Five Year Plan scenario). We compared the $\mathrm{CO}_{2}$ peak levels of different datasets in three scenarios to present how the data revision affects peak level changes. The details can be found in Supplementary 2.

In a sectoral mitigation analysis, we derived the sectoral $\mathrm{CO}_{2}$ emissions (from 2005 to 2014) from the previously constructed $\mathrm{CO}_{2}$ emission inventory of the 2015 data and 2010 data and collected sectoral GDP data from the China Statistics Yearbooks (2006-2015). Based on the sectoral $\mathrm{CO}_{2}$ and GDP, the historical carbon intensity from 2005 to 2014 can be calculated before we project the sectoral carbon intensity using the trend analysis (in Supplementary 2). Notably, the sectoral carbon intensity for key sectors is projected from 2005 to 2020 only because mitigation policy was first included in sectoral economic plans in 2005; this intensity may present wide variations and might be difficult to precisely estimate over longer periods. Using the sectoral projection, we 
evaluated the impacts of data revisions on achieving sectoral mitigation targets. 
Table 2. Summary of Scenarios and Assumptions

\begin{tabular}{|c|c|c|c|c|c|c|c|}
\hline Scenarios & \multicolumn{2}{|c|}{ Indicators } & 2016-2020 & 2021-2025 & $2026-2030$ & 2031-2035 & Description \\
\hline \multirow{3}{*}{$\begin{array}{l}\text { 12th Five } \\
\text { Year Plan } \\
\text { Scenario }\end{array}$} & \multicolumn{2}{|c|}{ Average GDP Growth } & $6.50 \%$ & $6 \%$ & $5.50 \%$ & $5 \%$ & \multirow{6}{*}{$\begin{array}{l}\text { GDP assumption derived from the 13th } \\
\text { Five Year Plan ( } 6.5 \% \text { for } 2016-2020 \text { ) and } \\
\text { extrapolated to } 2035 \text { by subtracting } 0.5 \% \\
\text { every } 5 \text { years. The carbon intensity is } \\
\text { projected using an exponential } \\
\text { regression based on intensity } \\
\text { (2011-2015) for the } 12 \text { th Five Year Plan } \\
\text { scenario and on the last } 5 \text { years for the } \\
\text { accelerated scenario. }\end{array}$} \\
\hline & Carbon & 2015 Data & $-4.59 \%$ & $-4.59 \%$ & $-4.59 \%$ & $-4.59 \%$ & \\
\hline & Intensity & 2010 Data & $-4.82 \%$ & $-4.82 \%$ & $-4.82 \%$ & $-4.82 \%$ & \\
\hline \multirow{3}{*}{$\begin{array}{l}\text { Accelerated } \\
\text { Scenario }\end{array}$} & \multicolumn{2}{|c|}{ Average GDP Growth } & $6.50 \%$ & $6 \%$ & $5.50 \%$ & $5 \%$ & \\
\hline & Carbon & 2015 Data & $-5.11 \%$ & $-4.99 \%$ & $-4.99 \%$ & $-5.00 \%$ & \\
\hline & Intensity & 2010 Data & $-5.29 \%$ & $-5.19 \%$ & $-5.19 \%$ & $-5.20 \%$ & \\
\hline \multirow{3}{*}{$\begin{array}{l}\text { Green\& } \\
\text { Stern } \\
\text { Scenario }\end{array}$} & \multicolumn{2}{|c|}{ Average GDP Growth } & $6.50 \%$ & $5.5 \%$ & $5.5 \%$ & $5.5 \%$ & \multirow{3}{*}{$\begin{array}{l}\text { GDP and carbon intensity assumpt } \\
\text { are derived from Green \& Stern's } \\
\text { research. }\end{array}$} \\
\hline & Carbon & 2015 Data & $-4.96 \%$ & $-5.44 \%$ & $-5.44 \%$ & $-5.44 \%$ & \\
\hline & Intensity & 2010 Data & $-4.96 \%$ & $-5.44 \%$ & $-5.44 \%$ & $-5.44 \%$ & \\
\hline
\end{tabular}

Note: The carbon intensity decline rate is an annual rate of decrease, and the GDP growth is the average rate for the respective period. 


\section{Results and Discussion}

\subsection{Challenges in reaching mitigation targets caused by data revisions}

Uncertain energy data imply uncertainty in achieving mitigation targets. First, we update the carbon intensity based on different energy statistics from 2000 to 2014 and extend the trajectory to 2035. As shown in Figure 1, because of the data revision, the mitigation benchmark (carbon intensity of 2005) increased by $5 \%$. Accordingly, the mitigation target required to reach the 2020 target increased from 19.47 to $20.49 \mathrm{Mt} / 10^{3}$ Yuan (CNY), and the target required to reach the 2030 target increased from 12.82 to $13.51 \mathrm{Mt} / 10^{3} \mathrm{CNY}$ (the blue and red dashed lines in Figure 1 refer to the $40 \%$ and $60 \%$ reductions, respectively). Therefore, the overall mitigation requirements were increased (the black line and brackets in the figure refer to the required carbon intensity before and after revision, respectively). The uncertainty introduced by the revised energy statistics raises doubts about China's ability to achieve its mitigation pledges for 2020 and 2030. For example, the revisions suggest that the originally reported mitigation achievements might be inflated. Based on an extrapolation of the 2010 data, China had achieved a 29.9\% carbon intensity reduction by 2014 (22.45 Mt $/ 10^{3} \mathrm{CNY}$ ) compared with the 2005 level; however, under the revision, this figure changes to a $25.23 \%$ reduction $\left(25.24 \mathrm{Mt} / 10^{3} \mathrm{CNY}\right)$.

Under the assumption that the recent trends will continue, we extended the trend-based carbon intensity to 2035 (see Methods) (Figure 1) and projected that China can achieve the $40 \%$ carbon intensity reduction target (2020 target) by 2018 , which represents a $41 \%$ carbon intensity reduction based on the 2010 data; however, the latest national data revision indicates that this target will not be met until 2020. This change may be attributed to the lower reduction rate of 
carbon intensity indicated by the 2015 data. The 2010 data showed that the average Chinese carbon intensity from 2000 to 2014 decreased at a rate of $2.2 \%$ per year, whereas after the revision, the rate of reduction was $1.2 \%$. Compared with the 2010 data for the same year, the lower reduction rate of the 2015 data leads to a higher carbon intensity, which causes the delay in meeting the mitigation targets. For the 2030 target, the 2010 statistics indicate that carbon intensity could be reduced by $60.7 \%$ by the end of 2026 , whereas the revision indicates a delay in achieving the mitigation targets until 2028. A comparison between the 2015 data and 2010 data indicates that the 2015 data are associated with higher mitigation requirements $\left(13.51 \mathrm{Mt} / 10^{3}\right.$ CNY for the 2020 target and 20.26 for the 2030 target, 5\% higher than the requirement for the 2010 data) but a lower mitigation rate $(1.2 \%$ for the 2015 data; $2.2 \%$ for the 2010 data), contributing to the uncertainty in the mitigation targets and $\mathrm{CO}_{2}$ trajectory.

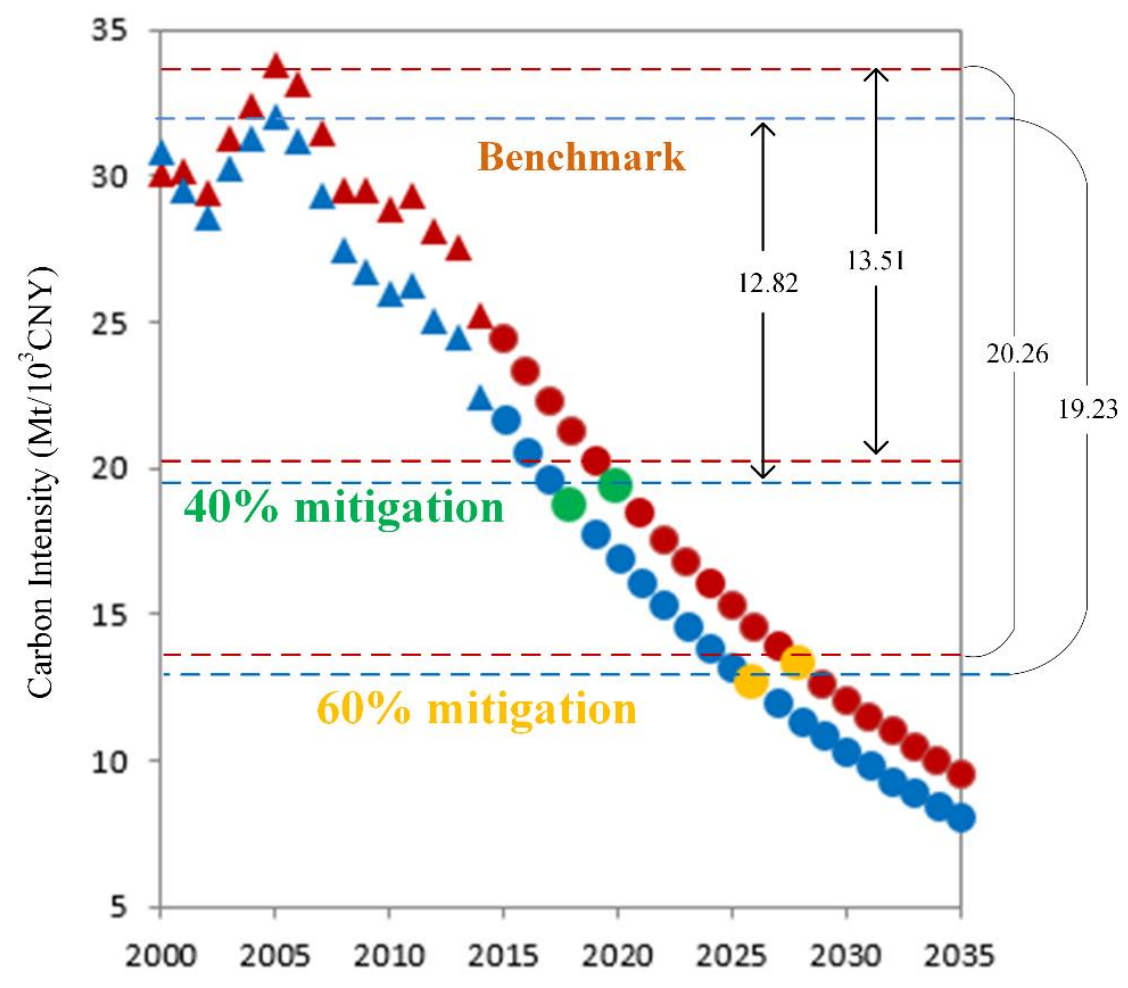

Figure 1. China carbon intensity trajectory (projection for 2015 to 2035). Triangles and circles 
indicate historical data and projection data, respectively. Red and blue indicate the 2015 and 2010 data, respectively. The red and blue lines crossing the triangles indicate a mitigation benchmark (2005 carbon intensity level). The red dashed line indicates the mitigation target for the 2015 data, and the blue dashed line indicates the mitigation target for the 2010 data. The green dots represent when the 2020 mitigation target is achieved, and the yellow dots represent when the 2030 mitigation target is achieved. The black line and brackets indicate the changes in mitigation requirements. The black arrows are for the 2020 mitigation target, and the parentheses show the 2030 mitigation target. The unit of the Y-axis is Mt $/ 10^{3}$ CNY. Note: CNY here is Chinese Yuan.

\subsection{Carbon space and peak level changes}

The revision of increased $\mathrm{CO}_{2}$ emissions directly changed past $\mathrm{CO}_{2}$ emissions in terms of the numbers and massively changed the trend slope of past emissions, which largely determined the future $\mathrm{CO}_{2}$ trajectory and the achievement of mitigation targets. As the key feature of the NDCs, the $\mathrm{CO}_{2}$ emission peak level has received widespread attention since late 2014, when the pledge was made. Using the simplest Kaya equation, we extended the $\mathrm{CO}_{2}$ emission trajectory illustrated by the two datasets to 2035 to reveal how the data revision affects the peak levels. Although many factors may contribute to the $\mathrm{CO}_{2}$ emission peak, mitigation policies play an important role in the peak levels. Because of the uncertain policy background, modellers employ scenario analyses to track China's $\mathrm{CO}_{2}$ trajectory via assumptions for different portfolios of policies (Liu et al., 2015a; Mi et al., 2016; Zhang et al., 2016); however, the uncertainty in the energy data leads to additional uncertainty in the scenario analyses. To illustrate this uncertainty, we created an accelerated scenario (see Methods) and used Green and Stern's projection assumption (Green and Stern, 2016) 
(see Methods) for $\mathrm{CO}_{2}$ emissions for comparative purposes and to evaluate the impacts of uncertain data. We found that the peak level changes dramatically and ranges from $12.38 \%$ to $17.85 \%$ of peak level by 2010 data for different scenarios due to data revision. Following the $\mathrm{CO}_{2}$ emission trend based on the $12^{\text {th }}$ Five Year Plan $\left(12^{\text {th }}\right.$ FYP $)$, the $\mathrm{CO}_{2}$ emissions should peak at 9.89 Gt in 2032; however, the 2015 data increase the peak level by 17.85\% to 11.65 Gt in 2034 (Figure 2). In the accelerated scenario, the 2015 data indicate that China would reach the peak of $10.76 \mathrm{Gt}$ $\mathrm{CO}_{2}$ in 2030, whereas the 2010 data suggest that this figure will be $9.21 \mathrm{Gt}^{C_{2}}$ in 2028 (Figure 2). However, according to Green and Stern's method, the peak level would be $10.13 \mathrm{Gt}$ and $9.08 \mathrm{Gt}$ $\mathrm{CO}_{2}$ for the 2015 and 2010 data, respectively, a difference of $12.38 \%$. When considering only the uncertainty from the scenarios (without regarding data revision), the uncertainty would be $15 \%$ for the 2015 data and 9\% for the 2010 data. To save the space and avoid confusion, we transit three scenarios of $12^{\text {th }}$ Five Year Plan, accelerated scenario and Green and Stern's scenarios in to Scenarios 1, 2, 3 in the Figure 2 respectively. However, the uncertainty in the $\mathrm{CO}_{2}$ peak might increase to $29 \%$. Notably, the data revision significantly changes the past trend, especially in the 2011-2015 data series, which greatly affects the $\mathrm{CO}_{2}$ trajectory. Although the 2015 data revision increased the $\mathrm{CO}_{2}$ emissions compared with the 2010 data, this revision also indicates a slower carbon intensity reduction rate than the 2010 data, implying less $\mathrm{CO}_{2}$ growth in the future. Therefore, the influence of data revision on the $\mathrm{CO}_{2}$ trajectory is not only a numeric change, in which the 2015 data revised $\mathrm{CO}_{2}$ emissions upward, but also changes the annual carbon intensity reduction rate during $2011-2015$ from $-4.82 \%$ to $-4.59 \%$. This difference affects the future $\mathrm{CO}_{2}$ trajectory, especially for scenarios 1 and 2. Other studies have presented estimates of the peak level. Zhang et al. (2016) applied a C-GEM model, the multiregional simulation model for global 
energy and economic systems, which is capable to capture the impact of policy by finding its effects on prices and goods, further people behaviours and then domestic economic activities. The research found that China's emissions would peak at 10 to $12 \mathrm{Gt} \mathrm{CO}_{2}$ based on different scenarios. Mi et al. (2016) adopted the input-output model to project a peak level of 11.20 to $12.59 \mathrm{Gt}$ based on different constraints. Liu et al. (2015a) used the Kaya identity model and estimated that the peak level might be 10.7 to $11.9 \mathrm{Gt}$ in different scenarios.

The changes in the $\mathrm{CO}_{2}$ trajectory generate additional under-reported $\mathrm{CO}_{2}$ emissions, which means that China would gain additional carbon space (or emissions quota for mitigation targets) because of the data revision. After the 2015 revision, the gap between the $\mathrm{CO}_{2}$ emissions calculated from the two energy datasets increased from $67 \mathrm{Mt}$ to $1045 \mathrm{Mt}$ every year from 2000 to 2014. During this period, $\mathrm{CO}_{2}$ emissions cumulatively increased by $7.4 \mathrm{Gt}$, which accounted for $7.8 \%$ of the total emissions based on the new data compared with the cumulative emissions from the pre-revised data. This change suggests that the $7.4 \mathrm{Gt}^{\mathrm{CO}_{2}}$ was under-reported before the data update in 2015. In the future, the carbon space will likely present increased uncertainty because of the data revision. The results of all the scenarios indicate significant differences in the carbon space, which ranges from 22.94 to $31.31 \mathrm{Gt}$ from 2015 to 2035 (36\% uncertainty). Moreover, the uncertainty related to the additional emission space implies that the global carbon budget before the revision was underestimated; thus, the global $\mathrm{CO}_{2}$ quota to reach the $2^{\circ} \mathrm{C}$ mitigation target is reduced (Friedlingstein et al., 2014). 




Figure 2 China's emission trajectory and projections (Unit: $\mathrm{Gt} \mathrm{CO}_{2}$ ).

Figure 2 compares the differences in peak level reached in the two datasets under the three scenarios. The peak levels reached by the 2015 data are 12.38\% (1114 Mt), 17.3\% (1487 Mt), and $17.85 \%(1764 \mathrm{Mt})$ higher than the peak levels projected by the 2010 data for the three scenarios, respectively. Scenario 1 is the 12th Five Year Plan scenario; Scenario 2 is the accelerated scenario; Scenario 3 is the Green and Stern scenario. In the 2010 data, the 2013 and 2014 emission data were extrapolated using the change rate of these two years in the 2015 data. Details can be found in the Methods section. 


\subsection{Implications for industrial mitigation}

Because China's mitigation initiatives are disaggregated into energy-intensive sectors, the revised $\mathrm{CO}_{2}$ emissions in the national inventory have resulted in uncertainty at the sectoral level. Together, three key industrial sectors consume more than $70 \%$ of the total energy: electricity supply (approximately 40\%), non-metal mineral product manufacturing (14\%), and ferrous metal smelting and pressing (20\%). These sectors have the highest emissions and lowest emission efficiencies (high emissions/low output) (Chen and He, 2016; Liu et al., 2012; Wang and Liang, 2013). Mitigation policies for these sectors are highly important and directly determine the mitigation results; therefore, we focus on how the data revision affects these sectors. Because of the importance of these sectors to mitigation accounts, these sectors are required to publish sectoral action plans for reducing their emissions and $\mathrm{CO}_{2}$ intensity (Wang et al., 2014). As indicated by the newly released $13^{\text {th }}$ Five Year Plan (2016-2020), non-metal mineral product manufacturing aims to decrease its carbon intensity by $15 \%$ by 2020 and ferrous metal smelting and pressing aims to decrease its carbon intensity by $10 \%$ by 2020 . Notably, carbon intensity for sector is the sectorial carbon emissions per unit sectorial GDP.

However, the 2015 data revision has a much greater effect on the steel and iron and cement industries than on the other sectors, which suggests that the historical energy consumption data for these two key sectors might be problematic. Because of the unique role of these sectors in the mitigation, any uncertainty in their energy data is important. The revision of energy data from 2000 to 2014 increased emissions from the iron and steel industry by an average of 17\% (range from $5 \%$ to $31 \%$ ), which was mainly induced by the energy required for steel production. The 
emissions from cement production increased by $5 \%$ (range from $-12 \%$ to $15 \%$ ). During 2005 to 2012, the revised emissions increased by $12 \%$ each year (Table 2S). If we assume that the latest 2015 data are reliable, these findings would indicate a $21 \%$ underestimate for the steel industry and a $12 \%$ underestimate for the cement industry from 2005 to 2012 (Table $2 \mathrm{~S}$ ). The mitigation achievements of the iron and steel industry from 2005 to 2012 decreased from $45 \%$ to $35 \%$ because of the lower mitigation rate in the 2015 data, and the cement industry showed a slight decrease from $60 \%$ to $58 \%$. The data revision in 2015 might make it more challenging to achieve mitigation targets. Based on the trend analysis, we extended the emissions to 2020 for the carbon intensity calculation. We found that the projected carbon intensity reduction from the iron and steel industry over the period of $13^{\text {th }}$ Five Year Plan would decline significantly from $12 \%$ to $8 \%$, while the carbon intensity reduction of the cement industry decreased from $34 \%$ to $28 \%$. Based on the trends observed in the latest data, the sectoral mitigation target for the iron and steel industry might not be achieved.

Raw coal plays a dominant role in the energy structures of these two energy-intensive sectors. However, revision in raw coal consumption and its related emissions are not same for the two sectors. For the cement industry, raw coal-related emissions from 2000 to 2012 increased by an average of $14 \%$ after the revision, especially after 2005 , since emissions were increased by an average of almost $30 \%$. Subsequently, the total sectoral emission increased by an average of $5 \%$ from 2000 to 2012 and 12\% after 2005 (details in Table 2S). The revision in raw coal consumed in the cement industry might indicate an underestimate of raw coal usage before 2015. However, there was an anomaly for the iron and steel industry between raw coal-related emissions and the sectoral emissions. From 2000 to 2008, coal-related emissions under the 2015 data were $10 \%$ 
lower than those in the 2010 data, whereas the total sectoral emissions in the 2015 data were $15 \%$ higher than those in the 2010 data. After 2008, the changes in the coal-related emissions in the 2015 data were in accordance with those of the sectoral emissions but only accounted for $5 \%$ of the sectoral emission changes (Table 3S). As the dominant energy type in the iron and steel industry, the trend in coal-related emissions should have matched that of total emissions. The opposite change may have profound implications. For the steel industry, we found that the emissions from raw coal decreased while the emissions from coke and other gas increased after the revision, especially for other gas, which showed a three-fold growth (Table 2S). This finding may imply that a proportion of the coke and other gas used in the steel industry might have been categorised as raw coal in previous statistics, which would have overestimated the previous reliance of the steel industry on raw coal before 2008 and underestimated the raw coal consumption since 2008 .

\section{Conclusion and policy recommendations}

$\mathrm{CO}_{2}$ emissions are the main target of global emission mitigation, and the sheer magnitude of $\mathrm{CO}_{2}$ emissions increases the importance of obtaining correct data because the uncertainties are closely correlated with the ability to achieve mitigation targets (Monni et al., 2004). This paper compares the difference in the 2015 energy data revision in China and shows how the large uncertainty impacts the achievement of national mitigation targets that are essential in global decarbonisation initiatives. After the energy statistics revisions, mitigation challenges increase by $5 \%$, and achieving national mitigation targets (and international pledges) might be postponed by two years, from 2018 to 2020 , to reach the $40 \%$ carbon intensity reduction target and from 2026 to 2028 to 
reach the $60 \%$ carbon intensity reduction target. This delay is due to the slower carbon intensity reduction rate in the 2015 data. The 2015 data revision increased the past $\mathrm{CO}_{2}$ emissions; therefore, extra carbon space (from 22.94 to $31.31 \mathrm{Gt}$ ) might be generated from 2015 to 2035 , and $\mathrm{CO}_{2}$ peak levels with the uncertainty varying from $12 \%$ to $29 \%$ might be induced by the revised energy statistics. In addition to the national mitigation targets, mitigation targets for key industrial sectors are affected by the data revision, in which raw coal consumption for the cement and iron and steel industries increased greatly. Although our study shows that achieving mitigation targets would not be derailed by the data revisions, the unexpected carbon space and lower carbon intensity reduction rate suggest that the mitigation challenges will exceed current estimates, especially for key mitigation sectors for which the data revision has altered sectoral mitigation prospects. Furthermore, the revisions have additional implications for global decarbonisation initiatives because the tremendous carbon space reported by the new data has long been underestimated. The remaining emission quota from 2015 with the $2{ }^{\circ} \mathrm{C}$ goal (66\% probability) is $1200 \mathrm{Gt} \mathrm{CO}_{2}$. With the new data, extra carbon space in China might compromise the total remaining emission quota, increasing the challenges for other countries with shrinking emission quotas. This paper clearly shows that the uncertainties in the past will be reflected in uncertainties in projections of the future.

The revised data show inconsistencies in the energy data; however, they also show the progress in the energy statistics system, as the gap between the updated national data and aggregated provincial data is decreasing (Guan et al., 2012; Shan et al., 2015). It appears plausible that the energy accounting system will improve as the gap is reduced, but the current institutional arrangement of a bottom-up energy accounting system still relies on energy accounting at a lower 
level, such as the city level, which requires highly accurate and reliable primary energy consumption data from manufacturers. Collecting these fundamental data is confronted with huge challenges such as local governments manipulating data for political benefits or a lack of control over small coal mines or factories, as described in previous research (Guan et al., 2012; Li et al., 2014; Zheng et al., 2014). In the current energy accounting institutions, more on-site surveys on energy data collection and accuracy checks with qualified labour would be helpful but costly. With the importance of China's energy statistics in the world, a well-established energy accounting system is urgently required to ensure consistency and accuracy instead of relying on National Economic Census data every 5 years to make adjustments. Alternative energy accounting approaches such as remote-sensing technology could be considered to monitor and verify $\mathrm{CO}_{2}$ emissions. 


\section{Acknowledgements}

All the data and results can be download freely from China Emission Accounts and Datasets

(CEADs) at http://www.ceads.net. This work was supported by the National Key R\&D Program of China (2016YFA0602604), the Natural Science Foundation of China $(71533005,41629501)$, the

UK Economic and Social Research Council (ES/L016028/1), Natural Environment Research Council (NE/N00714X/1), British Academy Grant (AF150310), China Scholarship Council (No. 201606510016) and the joint Leverhulme Trust and Social Sciences Faculty Postgraduate Studentships at the University of East Anglia. We also acknowledge the editor and referees for their time and constructive suggestions. 


\section{References}

Akimoto, H., Ohara, T., Kurokawa, J. ichi, Horii, N., 2006. Verification of energy consumption in China during 1996-2003 by using satellite observational data. Atmos. Environ. 40, 7663-7667. doi:10.1016/j.atmosenv.2006.07.052

Andres, R.J., Boden, T.A., Higdon, D., 2014. A new evaluation of the uncertainty associated with CDIAC estimates of fossil fuel carbon dioxide emission. Tellus B 66, 1-15. doi:10.3402/tellusb.v66.23616

Blanco, G., Gerlagh, R., Suh, S., Barrett, J., de Coninck, H.C., Diaz Morejon, C.F., Mathur, R., Nakicenovic, N., Ofosu Ahenkora, A., Pan, J., Pathak, H., Rice, J., Richels, R., Smith, S.J., Stern, D.I., Toth, F.L., Zhou, P., 2014. Drivers, Trends and Mitigation, Climate Change 2014: Mitigation of Climate Change. Contribution of Working Group III to the Fifth Assessment Report of the Intergovernmental Panel on Climate Change.

Bruckner, T., Bashmakov, I.A., Mulugetta, Y., Chum, H., Navarro, A. de la V., Edmonds, J., Faaij, A., Fungtammasan, B., Garg, A., Hertwich, E., Honnery, D., D, I., Kainuma, M., Khennas, S., Kim, S., Nimir, H.B., Riahi, K., Strachan, N., Wiser, R., Zhang, X., 2014. Energy Systems, in: Climate Change 2014: Mitigation of Climate Change. Contribution of Working Group III to the Fifth Assessment Report of the Intergovernmental Panel on Climate Change. pp. 511597.

Chen, W., He, Q., 2016. Intersectoral burden sharing of CO2 mitigation in China in 2020. Mitig. Adapt. Strateg. Glob. Chang. 21, 1-14. 
doi:10.1007/s11027-014-9566-3

Friedlingstein, P., Andrew, R.M., Rogelj, J., Peters, G.P., Canadell, J.G., Knutti, R., Luderer, G., Raupach, M.R., Schaeffer, M., van Vuuren, D.P., Le Quéré, C., 2014. Persistent growth of $\mathrm{CO} 2$ emissions and implications for reaching climate targets. Nat. Geosci. 7, 709-715. doi:10.1038/ngeo2248

Green, F., Stern, N., 2016. China's changing economy: implications for its carbon dioxide emissions. Clim. Policy 0, 1-15. doi:10.1080/14693062.2016.1156515

Gregg, J.S., Andres, R.J., Marland, G., 2008. China: Emissions pattern of the world leader in $\mathrm{CO} 2$ emissions from fossil fuel consumption and cement production. Geophys. Res. Lett. 35, L08806. doi:10.1029/2007GL032887

Guan, D., Liu, Z., Geng, Y., Lindner, S., Hubacek, K., 2012. The gigatonne gap in China's carbon dioxide inventories. Nat. Clim. Chang. 2, 672-675. doi:10.1038/nclimate1560

Guan, L., Sun, G., Cao, S., 2011. China's bureaucracy hinders environmental recovery. Ambio 40, 96-99. doi:10.1007/s13280-010-0112-6

Hong, C., Zhang, Q., He, K., Guan, D., Li, M., Liu, F., Zheng, B., 2016. Variations of China's emission estimates response to uncertainties in energy statistics. Atmos. Chem. Phys. Discuss. doi:10.5194/acp-2016-459

IPCC, 2006. 2006 IPCC Guidelines for National Greenhouse Gas Inventories. 2006 IPCC Guidel. Natl. Greenh. Gas Invent. 3, 1-40.

Kaya, Y., 1990. Impact of Carbon Dioxide emission control on GNP growth: Interpretation of proposed scenarios, in: Paper Presented to the IPCC Energy and 
Industry Subgroup, Response Strategies Working Group.

Korsbakken, J.I., Peters, G.P., Andrew, R.M., 2016. Uncertainties around reductions in China's coal use and CO2 emissions. Nat. Clim. Chang. 6, 687-690. doi:10.1038/nclimate2963

Li, H., Wu, T., Zhao, X., Wang, X., Qi, Y., 2014. Regional disparities and carbon “outsourcing”: The political economy of China's energy policy. Energy 66, 950958. doi:10.1016/j.energy.2014.01.013

Li, H., Zhao, X., Yu, Y., Wu, T., Qi, Y., 2016. China’s numerical management system for reducing national energy intensity. Energy Policy 94, 64-76. doi:10.1016/j.enpol.2016.03.037

Liu, Z., 2015. China's Carbon Emissions Report 2015. doi:http://belfercenter.ksg.harvard.edu/files/carbon-emissions-report-2015-final.p df

Liu, Z., Geng, Y., Lindner, S., Guan, D., 2012. Uncovering China's greenhouse gas emission from regional and sectoral perspectives. Energy 45, 1059-1068. doi:10.1016/j.energy.2012.06.007

Liu, Z., Guan, D., Moor, S., Su, J., Zhang, Q., 2015a. Climate policy: Steps to China's carbon peak. Nature 522, 279-281.

Liu, Z., Guan, D., Wei, W., Davis, S.J., Ciais, P., Bai, J., Peng, S., Zhang, Q., Hubacek, K., Marland, G., Andres, R.J., Crawford-Brown, D., Lin, J., Zhao, H., Hong, C., Boden, T.A., Feng, K., Peters, G.P., Xi, F., Liu, J., Li, Y., Zhao, Y., Zeng, N., He, K., 2015b. Reduced carbon emission estimates from fossil fuel combustion and 
cement production in China. Nature 524, 335-338. doi:10.1038/nature14677

Ma, B., Song, G., Zhang, L., Sonnenfeld, D.A., 2014. Explaining sectoral discrepancies between national and provincial statistics in China. China Econ. Rev. 30, 353-369. doi:10.1016/j.chieco.2014.07.004

Marland, G., Hamal, K., Jonas, M., 2009. How uncertain are estimates of CO2 emissions? J. Ind. Ecol. 13, 4-7. doi:10.1111/j.1530-9290.2009.00108.x

Mi, Z., Meng, J., Guan, D., Shan, Y., Liu, Z., Wang, Y., Feng, K., Wei, Y.-M., 2017. Pattern changes in determinants of Chinese emissions. Environ. Res. Lett. 12, 74003. doi:10.1088/1748-9326/aa69cf

Mi, Z., Wei, Y.-M., Wang, B., Meng, J., Liu, Z., Shan, Y., Liu, J., Guan, D., 2016. Socioeconomic impact assessment of China's CO2 emissions peak prior to 2030. J. Clean. Prod. doi:10.1016/j.jclepro.2016.11.055

Monni, S., Syri, S., Savolainen, I., 2004. Uncertainties in the Finnish greenhouse gas emission inventory. Environ. Sci. Policy 7, 87-98. doi:10.1016/j.envsci.2004.01.002

NBS(NationalBureau ofStatistics), n.d. China Energy Statistical Yearbook. China Statistics Press, Beijing.

NDRC(National Development and Reform Commission), 2015. Outline of China 13th $\begin{array}{lllll}\text { Five } & \text { Year } & \text { Plan } & \text { [WWW }\end{array}$ http://sh.xinhuanet.com/2016-03/18/c_135200400.htm (accessed 12.13.16).

Peters, G., Weber, C., Liu, J., 2007. Construction of Chinese energy and emissions inventory (supporting information). Reports Work. Pap. from Norweigian Univ. 
Sci. Technol. Ind. Ecol. Progr. 1-21.

Qi, Y., Stern, N., Wu, T., Lu, J., Green, F., 2016. China's post-coal growth. Nat. Geosci. 9, 564-566. doi:10.1038/ngeo2777

Qi, Y., Wu, T., 2013. The politics of climate change in China. Wiley Interdiscip. Rev. Clim. Chang. 4, 301-313. doi:10.1002/wcc.221

Shan, Y., Liu, J., Liu, Z., Xu, X., Shao, S., Wang, P., Guan, D., 2015. New provincial CO2 emission inventories in China based on apparent energy consumption data and updated emission factors. Appl. Energy. doi:10.1016/j.apenergy.2016.03.073

Shan, Y., Liu, Z., Guan, D., 2016. CO2 emissions from China's lime industry. Appl. Energy 166, 245-252. doi:10.1016/j.apenergy.2015.04.091

Sinton, J., 2001. Accuracy and reliability of China's energy statistics. China Econ. Rev. 12, 373-383. doi:10.1016/S1043-951X(01)00067-0

van Ruijven, B.J., Weitzel, M., den Elzen, M.G.J., Hof, A.F., van Vuuren, D.P., Peterson, S., Narita, D., 2012. Emission allowances and mitigation costs of China and India resulting from different effort-sharing approaches. Energy Policy 46, 116-134. doi:10.1016/j.enpol.2012.03.042

Wang, C., Lin, J., Cai, W., Liao, H., 2014. China's carbon mitigation strategies: Enough? Energy Policy 73, 47-56. doi:10.1016/j.enpol.2014.05.041

Wang, X., 2011. On China's energy intensity statistics: Toward a comprehensive and $\begin{array}{llll}\text { transparent } & \text { indicator. } & \text { Energy } & \text { Policy }\end{array}$ doi:10.1016/j.enpol.2011.08.050

Wang, Y., Liang, S., 2013. Carbon dioxide mitigation target of China in 2020 and key 
economic sectors. Energy Policy 58, 90-96. doi:10.1016/j.enpol.2013.02.038

Zhang, X., Karplus, V.J., Qi, T., Zhang, D., He, J., 2016. Carbon emissions in China: How far can new efforts bend the curve? Energy Econ. 54, 388-395. doi:10.1016/j.eneco.2015.12.002

Zheng, H., Wang, X., Cao, S., 2014. The land finance model jeopardizes China's sustainable development. Habitat Int. 44, 130-136. doi:10.1016/j.habitatint.2014.05.008 


\section{Table Caption}

Table 1 Comparison between 2015 data, 2010 data, 2006 data and Original data

Note: Mtce=Million tons coal equivalent; $\mathrm{Mt}=$ Million tons. Underlined data indicate the revised data for each dataset.

\section{Table 2 Summary of Scenarios and Assumptions}

Note: The carbon intensity decline rate is an annual rate of decrease, and the GDP growth is the average rate for the respective period. 


\section{Figure Caption}

Figure 1. China carbon intensity trajectory (projection for 2015 to 2035). Triangles and circles indicate historical data and projection data, respectively. Red and blue indicate the 2015 and 2010 data, respectively. The red and blue lines crossing the triangles indicate a mitigation benchmark (2005 carbon intensity level). The red dashed line indicates the mitigation target for the 2015 data, and the blue dashed line indicates the mitigation target for the 2010 data. The green dots represent when the 2020 mitigation target is achieved, and the yellow dots represent when the 2030 mitigation target is achieved. The black line and brackets indicate the changes in mitigation requirements. The black arrows are for the 2020 mitigation target, and the parentheses show the 2030 mitigation target. The unit of the Y-axis is Mt $/ 10^{3} \mathrm{CNY}$. Note: CNY here is Chinese Yuan.

\section{Figure 2 China's emission trajectory and projections (Unit: $\mathrm{Gt}_{\mathrm{CO}}$ ).}

Figure 2 compares the differences in peak level reached in the two datasets under the three scenarios. The peak levels reached by the 2015 data are $12.38 \%$ (1114 Mt), 17.3\% (1487 Mt), and $17.85 \%(1764 \mathrm{Mt})$ higher than the peak levels projected by the 2010 data for the three scenarios, respectively. Scenario 1 is the 12th Five Year Plan scenario; Scenario 2 is the accelerated scenario; Scenario 3 is the Green and Stern scenario. In the 2010 data, the 2013 and 2014 emission data were extrapolated using the change rate of these two years in the 2015 data. Details can be found in the Methods section. 